\title{
A mitochondria targeting Mn nanoassembly of BODIPY for LDH-A, mitochondria modulated therapy and bimodal imaging of cancer
}

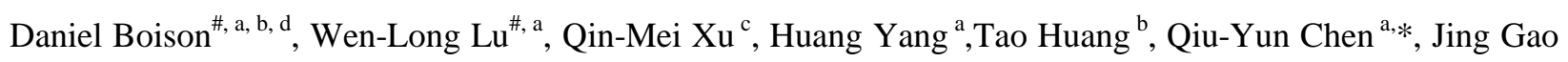
b,*, Yao Zhao e

${ }^{a}$ School of Chemistry and Chemical engineering, Jiangsu University, Zhenjiang, 212013, P. R. China. Tel.: +860511 8879800; Fax: +86051188791602;

${ }^{b}$ School of Pharmacy, Jiangsu University, Zhenjiang, 212013, P.R. China

${ }^{c}$ Jiangsu Key Laboratory of Molecular and Functional Imaging, Department of Radiology, Zhongda Hospital, Medical School, Southeast University, Nanjing, 210009, P. R. China

${ }^{d}$ School of Biological Sciences, Department of Biochemistry, University of Cape Coast, Cape Coast, Ghana

${ }^{e}$ Beijing National Laboratory for Molecular Science; CAS Key Laboratory of Analytical Chemistry for Living Biosystems, Institute of Chemistry, Chinese Academy of Sciences, Beijing, 100190, P.R. China.

Corresponding author

*Tel.: +86 0511 8879800; Fax: +86 $051188791602{ }^{a}$ School of Chemistry and Chemical engineering, ${ }^{b}$ School of Pharmacy, Jiangsu University, Zhenjiang, 212013, P. R. China.

*E-mail address: chenqy@ujs.edu.cn (Q.Y. Chen); jinggao@ujs.edu.cn (J. Gao)

\# Authors are equal contribution to this paper. 


\begin{abstract}
HIF-1 $\alpha$ and LDH-A are important targets for hypoxia-driven drug resistance. Mitochondria targeted fluorescent manganese(II)-complexes can be used as potential fluorescence imaging agents, MRI contrast agents and HIF-1 $\alpha$ and LDH-A involved anticancer complexes. In this study, a fluorescent manganese(II) nanoparticle, labeled as (PEG-Mn-BDA), was synthesized and used as both fluorescent and MRI imaging agents in cancer cells. In vitro bioassay results indicate that PEG-Mn-BDA was able to inhibit LDH-A activity and depolarize mitochondrial membrane potential with the generation of intracellular ROS, which contributed to the induction of apoptosis. Moreover, the pro-apoptotic protein, caspase 3 was highly expressed. In vivo, PEG-Mn-BDA could also exert inhibition on a mouse hepatocellular carcinoma xenograft. These results suggest that mitochondria targeted PEG-Mn-BDA was able to simultaneously induce selective inhibition on cancer cells and a mouse carcinoma xenograft, label cancer cells with fluorescence and enhance MRI contrast. Therefore, PEG-Mn-BDA is a good candidate for cancer treatment and imaging.
\end{abstract}

Keywords: Anticancer; Manganese nanoparticle; Mitochondria; Apoptosis, Imaging 


\section{Introduction}

Mitochondria play an important role in suppression of tumor growth as they could determine the aberrant energetic metabolism of malignant cells and regulate cell death by apoptosis and necrosis. Cancer cells exhibit an extensive metabolic reprogramming that renders them more susceptible to mitochondrial perturbations than non-immortalized cells [1, 2]. Cancer cells activate glycolysis to meet their energy demands [3]. Under hypoxia, mitochondrial function alterations such as decreased production of ATP, calcium buffering capacity, stimulation of reactive oxygen species, loss of membrane potential, and release of pro-apoptotic proteins from the mitochondrial intermembrane space, are involved [4]. Hypoxia-inducible factor (HIF) is a common link between $\mathrm{O}_{2}$ availability, malignant progression, and changes in cancer metabolism [5]. HIF regulates the energy metabolism by triggering a switch from mitochondrial oxidative phosphorylation to anaerobic glycolysis, increasing the expression of genes that encode glycolytic enzymes and glucose transporters [6]. Conversely, changes in key modulators of cancer metabolism can also regulate HIF functions. Hence, targeted inhibition of HIF-1 $\alpha$ is new pathway to cancer therapy. Lactate dehydrogenase (LDH) plays a vital role in the process of glycolysis because it catalyzes the transformation of pyruvate to lactate and hence is an attractive therapeutic target. High levels of LDH-A have been documented in human cancers which makes it an attractive target $[7,8]$. The inhibition of LDH-A suppresses the conversion of pyruvate to lactate and increases the conversion of pyruvate into acetyl-CoA. The generation of the acetyl-CoA causes an increase in the quantities of NADH and FADH2 delivered to ETC and increase ROS production, which leads to oxidative intracellular stress, and induction of mitochondrial pathway apoptosis $[9,10]$. In particular, HIF-1 $\alpha$ and LDHA are important targets for hypoxia-driven drug resistance. Novel drugs that regulate metabolic pathways in multiple myeloma, specifically targeting LDH-A, can be beneficial to inhibit tumor growth and overcome drug resistance [11].

Recently, we found that $\mathrm{Mn}$ (II) complexes with ligand containing di(pyridylmethyl)amine and pyrrolketone could attenuate the activity of LDH-A signaling of the cancer cellsthrough HIF-1 $\alpha$ involved pathway 
[12]. Manganese(II) complexes of N-substituted di(picolyl)amines (dpa) could act as multifunctional complexes that inhibit the proliferation of cancer cells by attenuating the absorption of $\mathrm{Ca}^{2+}$ in mitochondria as well as disproportionation of $\mathrm{H}_{2} \mathrm{O}_{2}$ [13]. Manganese (Mn) is an essential metal found in a variety of biological tissues and plays important role as a cofactor in many enzymatic reactions, including the anti-oxidant enzyme superoxide dismutase, as well as enzymes involved in neurotransmitter synthesis and metabolism in the brain [14], which is necessary for normal functioning of a variety of physiological processes including amino acid, lipid, protein and carbohydrate metabolism [15]. This makes manganese compounds biocompatible entities which are less harmful to the patients and are therefore more safe [16].We have shown from our previous studies that manganese(II) complexes were able to induce apoptosis and autophagy by targeting mitochondria through generation of ROS and disruption of mitochondrial membrane transition pore [17-19]. Moreover, manganese(II) complexes are attractive as potential magnetic resonance image (MRI) contrast agents since they have relatively high electronic spins (5/2) [20-22]. Therefore, fluorescence manganese-complexes can be potential fluorescence imaging (FI) agents, MRI contrast agents and mitochondria target anticancer complexes. Combining MRI and FI can compensate for the deficiencies of each individual modality. The noninvasive MRI can be used for preoperative planning by providing the macroscopic outline of the tumor, while high resolution FI can allow direct intraoperative visualization of tumor margins ensuring complete surgical resection of tumors and sparing of normal tissue [23]. Drugs can be designed so as to bring different functionalities onto a single nanoplatform, e.g., for not only detecting the tumor site but also for monitoring tumor response to drug treatment [24, 25]. For example, patients may receive the triple agent-loaded NPs at the time of detection of tumor sites by MRI for preparation of surgery. The anticancer agent therein will provide neoadjuvant chemotherapy to shrink the tumor before its complete resection via image-guided surgery. Lastly, PEG nanoparticles are biocompatible, neutral, hydrophilic molecules in biological fluids, which help to improve the dispersity and blood circulation of the metallic compound they are bound to [26]. In this study, a fluorescence manganese polyethylene glycol nanoparticle, [PEG-NHCH $\left.\mathrm{COOMnCl}_{2} \mathrm{~m}-\mathrm{BDA}\right)$ ], (labelled as PEG-Mn-BDA, m-BDA=8-[di(2-picolyl)amine-3-benzyl]-4,4-difluoro-1,3,5,7-tetramethyl-4-bora-3a,4a-diazas-indacene), was investigated for the anti-proliferative activities, selectivity of PEG-Mn-BDA and bimodal imaging potentials. 


\section{Materials and Methods}

\subsection{Chemicals and Reagents}

The compounds, 8-[di(2-picolyl)amine-3-benzyl]-4,4-difluoro-1, 3, 5, 7-tetramethyl-4-bora-3a,4a-diaza-sindacene (m-BDA) and PEG-NHCH${ }_{2} \mathrm{COOH}(\mathrm{Mw}, 2000)$ were synthesized according to previously reported method $[27,28]$. Stock solution of m-BDA was prepared in $100 \%$ DMSO and PEG-Mn-BDA was prepared in water. 3-(4,5-Dimethylthiazol-2-yl)-2,5-diphenyl-2H-tetrazolium bromide (MTT) was from Amresco. Rhodamine 123 was from Invitrogen. The 2',7'-dichlorofluorescin diacetate (DCFH-DA) kit was purchased from the Beyotime Institute of Biotechnology (Nantong, China). Antibodies against $\beta$-actin, caspase-3 and LDH-A were from Santa Cruz Biotechnology, Inc. (Santa Cruz, CA, USA). N-acetyl cysteine (NAC), cyclosporine A (CsA), cobalt(II) chloride $\left(\mathrm{CoCl}_{2}\right)$ and deferoxamine (DFO) were purchased from Sigma-Aldrich. All other chemicals were of high purity and were from commercial sources.

\subsection{Synthesis of [PEG-NHCH $\mathrm{H}_{2} \mathrm{COOMnCl(m-BDA)]} \mathrm{(labeled} \mathrm{as} \mathrm{PEG-Mn-BDA)}$}

PEG-NHCH${ }_{2} \mathrm{COOH}(1.3 \mathrm{~g}, 0.25 \mathrm{mmol})$ was then dissolved in $8 \mathrm{~mL}$ ethanol, followed by addition of $\mathrm{MnCl}_{2} \cdot 4 \mathrm{H}_{2} \mathrm{O}(70 \mathrm{mg}, 0.35 \mathrm{mmol})$ and refluxed for $6 \mathrm{~h}$ under $80^{\circ} \mathrm{C}$. Finally, the solution was dialyzed using dialysis bag (2000) in ethanol:water (2:1) for $12 \mathrm{~h}$ and after vacuum drying, and a light yellow solid was obtained. Then the light yellow solid was dissolved in $10 \mathrm{~mL}$ ethanol, followed by addition of m-BDA (15 mg, $0.03 \mathrm{mmol}$ ) and refluxed for $6 \mathrm{~h}$ under $80{ }^{\circ} \mathrm{C}$. Finally, the solution was dialyzed in ethanol for $12 \mathrm{~h}$ and after vacuum drying, the red solid [PEG-NHCH $2 \mathrm{COOMnCl(m-BDA)]} \mathrm{(labeled} \mathrm{as} \mathrm{PEG-Mn-BDA)} \mathrm{was} \mathrm{obtained}$ with $63 \%$ yield. The PEG-Mn-BDA (100 mg) was dissolved in $15 \mathrm{~mL}$ of $\mathrm{CH}_{2} \mathrm{Cl}_{2}$ :DMF (20:1), then $5 \mathrm{~mL}$ of water was added to form emulsion. After dropwise addition of $20 \mathrm{~mL}$ cyclohexane, the nanoassemblies of PEG-Mn-DBA were obtained after centrifugation.

\subsection{Characterization of PEG-Mn-BDA}


TEM was performed at room temperature on a JEOL JEM-200CX transmission electron microscope using an accelerating voltage of $200 \mathrm{kV}$ to examine the morphology of PEG-Mn-BDA. Mean particle diameter and size distribution of PEG-Mn-BDA were measured by dynamic light scattering (DLS) using a Brookhaven 90 plus particle size analyzer. FT-IR characterizations were performed using a Nicolet Nexus 470 FT-IR spectrophotometer in the wave number range of $4000-400 \mathrm{~cm}^{-1}$. The electronic absorption spectrum was recorded using a UV-2450 UV-vis spectrophotometer at room temperature. The concentration of manganese in PEG-Mn-BDA was measured in triplicate using an atomic absorption spectrometer. The stability of PEG-MnBDA in PBS buffer at both room temperature and $37^{\circ} \mathrm{C}$ was investigated by measuring the particle size over time using a Brookhaven 90 plus particle size analyzer.

\subsection{Cell lines and cell culture}

WRL-68, SMMC-7721, HCT-116 and HepG-2 were obtained from Cancer Cell Repository (Shanghai cell bank). Cells were maintained in DMEM medium or MEM medium (Gibco, USA) supplemented with 10 $\%(\mathrm{v} / \mathrm{v})$ heat-inactivated fetal bovine serum and antibiotics $(100 \mathrm{U} / \mathrm{ml}$ penicillin and $100 \mathrm{U} / \mathrm{ml}$ streptomycin) at $37{ }^{\circ} \mathrm{C}$ in a humidified atmosphere of $5 \% \mathrm{CO}_{2}$ and $95 \%$ air.

\subsection{Animal experiment}

Female imprinting control region (ICR) mice (6-8 weeks old) were purchased from the Comparative Medicine Research Center of Yangzhou University. The mice were maintained on a standard diet and water was made freely available. For xenograft studies, $1 \times 10^{7} \mathrm{Hep}-\mathrm{A}$ cells were injected subcutaneously into the ICR mice. [After cell injection, the mice were randomly assigned into four experimental groups (10 per group)]. The groups of mice were separately treated with 5-FU (20 mg/kg, intraperitoneal injection, positive control) or PEG-Mn-BDA (20 or $40 \mathrm{mg} / \mathrm{kg}$, intragastric administration) or equal volume of vehicle once a day for 10 days. Tumor volumes were measured with a caliper and calculated using the equation volume $=\mathrm{ab}^{2} / 2$, where "a" is the maximal width and "b" is maximal orthogonal width. The tumor weights of the treated (Tw) and control $(\mathrm{Cw})$ groups were measured on the last day of the experiment and the percentage of tumor growth inhibition was calculated as follows: Inhibition $(\%)=[1-(\mathrm{Tw} / \mathrm{Cw})] \times 100$. Animal welfare and experimental procedures 
were carried out strictly in accordance with the guide for the Care and Use of Laboratory Animals (The Ministry of Science and Technology of China, 2006) and the related ethical regulations of our university. All efforts were made to minimize the suffering of the animals and to reduce the number of animals used.

\subsection{Cell proliferation assay}

Cell viability was assessed by MTT assay. Cells were plated in 96-well culture plates at an initial density of 4000 cells in $100 \mu \mathrm{l}$ medium per well. After $24 \mathrm{~h}$ of cell growth, various concentrations of BDA and PEGMn-BDA were added to each well and incubation was continued for indicated time period. At the required time point, $100 \mu \mathrm{L}$ of MTT solution $(1 \mathrm{mg} / \mathrm{ml})$ was added to each well. The plates were incubated for an additional $4 \mathrm{~h}$ at $37^{\circ} \mathrm{C}$. The medium was removed and $100 \mu \mathrm{L}$ of DMSO was added to each well to dissolve the formazan. The absorbance was measured at $570 \mathrm{~nm}$ using a plate reader (Spectra MaxGemini, Molecular Devices Corporation). The rate of inhibition was calculated as follows: Rate of Inhibition $=(1-$ OD570 drug treated/ OD570 control $) \times 100$. The $50 \%$ Inhibition of control growth $\left(\mathrm{IC}_{50}\right)$ values were determined graphically from the growth inhibition curves obtained after a $48 \mathrm{~h}$ exposure to compounds BDA and PEGMn-BDA, using the software from China Pharmaceutical University. Images of the cell morphology were taken with an inverted microscope (TS100, Nikon) at random fields.

\subsection{Cellular uptake and imaging}

Human cancer cell line SMMC-7721 was obtained from Cancer Cell Repository (Shanghai cell bank) and cultured in DMEM medium (Gibco, USA), supplemented with 10\% (V/V) heat-inactivated fetal bovine serum, antibiotics (100 $\mathrm{U} \mathrm{mL}^{-1}$ penicillin and $100 \mathrm{U} \mathrm{mL}^{-1}$ streptomycin), at $37{ }^{\circ} \mathrm{C}$ in a humidified atmosphere of $5 \%$ $\mathrm{CO}_{2}$. SMMC-7721 cells $\left(2.4 \times 10^{4}\right)$ were seeded into 24 -well plates (every plate was $\left.100 \mu \mathrm{L}\right)$ for $24 \mathrm{~h}$, and then $10 \mu \mathrm{M}$ of m-BDA and $10 \mu \mathrm{M}$ of PEG-Mn-BDA were added and incubated for $3 \mathrm{~h}$. At last, cells were washed with PBS twice to remove any trace of medium from the compounds. For fluorescence analysis, compounds uptake and imaging of SMMC-77211 cells were observed using a Laser Scanning Confocal Microscope. The bright and fluorescence imaging of cells (ex. $555 \mathrm{~nm}$ ) were recorded and analyzed. For MRI analysis, the cells were imaged using Siemens Trio 3.0 T MR Imager at room temperature. 


\subsection{Western blot analysis}

Whole-cell lysates and tissue lysates were prepared from treated cells with lysis buffer $(0.5 \%$ Triton X$100,100 \mathrm{mM}$ Tris- $\mathrm{HCl}, 150 \mathrm{mM} \mathrm{NaCl}$ and $0.1 \mathrm{U} / \mathrm{ml}$ aprotinin) for $30 \mathrm{~min}$ on ice and centrifuged at $12000 \mathrm{~g}$ for 6 min. Equal amounts of total protein lysates were separated on $10 \%$ polyacrylamide gels, transferred onto PVDF membranes and probed with the following primary antibody against caspase-3 (1:1000), LDH-A (1:1000) and $\beta$-Actin $(1: 2000)$ at $4{ }^{\circ} \mathrm{C}$ overnight. Then the membranes were incubated for $1 \mathrm{~h}$ at room temperature with the appropriate horseradish peroxidase-conjugated secondary antibody. Target proteins were detected by the ECL system (Millipore Corporation, Billerica, USA).

\subsection{Mitochondrial membrane potential assay}

Mitochondrial membrane potential (MMP) reflects the functional state of the mitochondria within cells. Changes in MMP in PEG-Mn-BDA-exposed SMMC-7721 cells were measured by the uptake of lipophilic cation rhodamine 123 (Rho 123) into mitochondria. This fluorescent dye is bound to the inner and outer membrane of mitochondria and undergoes a red shift (decrease) in fluorescence during membrane depolarization. After incubation with PEG-Mn-BDA, the adherent cells were trypsinized and transferred into a 75-mm Falcon polystyrene tube and then pelleted by centrifugation at 1,000 $\mathrm{g}$ for $4 \mathrm{~min}$ at room temperature and washed once with PBS. The cells were then resuspended in $1 \mathrm{~mL}$ of Rho $123(10 \mu \mathrm{g} / \mathrm{mL})$ for $30 \mathrm{~min}$ in the dark, washed twice with PBS and resuspended in PBS. The samples were analyzed for fluorescence using a fluorescence spectrophotometer Model CARY Eclipse (VARIAN, USA), at $488 \mathrm{~nm}$ excitation and $530 \mathrm{~nm}$ emission wavelengths.

\subsection{Measurement of intracellular ROS production}

The intracellular generation of ROS was analyzed with the probe DCFH-DA. Cells were incubated with $10 \mu \mathrm{M}$ DCFH-DA at $37{ }^{\circ} \mathrm{C}$ for $20 \mathrm{~min}$. Then DCF fluorescence distribution of $1 \times 10^{4}$ cells was measured with fluorescence spectrometry (Spectra MaxGemini, Molecular Devices Corporation) at excitation wavelength of 
$488 \mathrm{~nm}$ and at an emission wavelength of $535 \mathrm{~nm}$. Morphological changes of cells were observed by fluorescence microscope (ECLIPSE Ti, Nikon).

\subsection{Detection of LDH activity}

The total LDH activity in cell lysates was examined according to the manufacturer's instructions of the LDH assay kit. Briefly, $2 \times 10^{5}$ cells were seeded in a 24 -well plate one day before assaying and all samples were analyzed in triplicate. Then cells were collected, washed and extracted for proteins to measure LDH activity. Results were normalized based upon total proteins.

\subsection{Statistical analysis}

Comparisons were made by one-way analysis of variance (ANOVA) followed by q-test. Differences were considered statistically significant when $\mathrm{p}<0.05$. All experiments were repeated at least 3 times. All graphs were created using GraphPad Prism 5 software.

Scheme 1: Synthetic routes of PEG-Mn-BDA.

\section{Results and discussions}

\subsection{Synthesis and characterization}

The synthetic route to PEG-Mn-BDA is shown in Scheme 1. PEG-Mn-BDA was successfully synthesized by the chelation of Mn(II) ions with amino acid modified PEG and BDA and purified by dialysis. The content of manganese in PEG-Mn-BDA was $14 \mu \mathrm{g} / \mathrm{mg}$. The IR spectra of PEG-Mn-BDA were shown in Fig. S1. The peak at $3430 \mathrm{~cm}^{-1}$ was attributed to the $\mathrm{O}-\mathrm{H}$ vibration. The aliphatic or aromatic $\mathrm{C}-\mathrm{H}$ stretching of $\mathrm{CH}, \mathrm{CH}_{2}$ and $\mathrm{CH}_{3}$ groups was observed around $2881 \mathrm{~cm}^{-1}$ and $3020 \mathrm{~cm}^{-1}$. The peak of PEG-Mn-BDA at $1713 \mathrm{~cm}^{-1}$ was attributed to the $\mathrm{C}=\mathrm{O}$ stretching of the $\mathrm{COOH}$. These peaks confirm the existence of $\mathrm{PEG}$, $-\mathrm{COOH}$ and 
aromatic groups in PEG-Mn-BDA. In UV-vis spectrum, the peaks of $210 \mathrm{~nm}$ and $500 \mathrm{~nm}$ (assigned to conjugated $\pi \rightarrow \pi^{*}$ transition) were the characteristic absorption peaks of m-BDA in PEG-Mn-BDA (Fig. S2) [27]. The coordination of $\mathrm{Mn}^{2+}$ with $\mathrm{m}-\mathrm{BDA}$ might have caused the blue shift of $\pi \rightarrow \pi^{*}$ transition of m-BDA which occurs at $264 \mathrm{~nm}$ to $220 \mathrm{~nm}$. A wider peak that occurred at $306 \mathrm{~nm}$ suggests metal-ligand interaction within PEG-Mn-BDA. The hydrophobic group of BDA and hydrophilic group of PEG (Mw. 2000) can selfassemble into nanoassemblies through water-in-oil emulsion methods. The maximum concentration of PEGMn-BDA nanoassembies in water is $5 \mathrm{mg} / \mathrm{mL}$. DSL data show that size of PEG-Mn-BDA nanoassemblies in water $(5 \mathrm{mg} / \mathrm{mL})$ was essentially unchanged at $37^{\circ} \mathrm{C}$ for one week. The TEM image showed that PEGMn-BDA had a rod-like structure with the size around $200 \mathrm{~nm}$ as measured by DLS (Fig. S3).

\subsection{Selective toxicity}

In order to examine the cytotoxicity of PEG-Mn-BDA on cancer cell lines, HCT-116 and SMMC-7721 cells were exposed to different concentrations of PEG-Mn-BDA for $24 \mathrm{~h}$ and the cell survival rate was then assessed by an MTT assay. Fig. 1A, 1B and 1C indicated that PEG-Mn-BDA induced high anti-proliferative effect on the cells and the relative cell survival rates at $13 \mu \mathrm{M}, 15 \mu \mathrm{M}$ and $41 \mu \mathrm{M}$ were shown in Table S1. PEG-Mn-BDA demonstrated significant selectivity towards the liver cancer cells (SMMC-7721) with respect to the non-malignant liver epithelial cells (WRL-68) (Fig. S4). The selective toxicity toward the cancer cells as against the non-cancer cells makes PEG-Mn-BDA a good candidate for antitumor agent. The differences in viability percentages between SMMC-7721 and WRL-68 were found to be $22.4 \%, 39.03 \%$ and $38.05 \%$ at concentrations of $3 \mu \mathrm{M}, 10 \mu \mathrm{M}$ and $30 \mu \mathrm{M}$ of m-BDA respectively. The differences in viability percentages between PEG-Mn-BDA and WRL-68 were found to be $33.19 \%, 48.25 \%$ and $60 \%$ at concentrations $3 \mu \mathrm{M}, 10$ $\mu \mathrm{M}$ and $30 \mu \mathrm{M}$ of PEG-Mn-BDA, respectively. The differences in viability percent for m-BDA and PEG-MnBDA were then plotted (Fig.S5). It was shown that at all the concentrations, PEG-Mn-BDA had higher viability percent difference than m-BDA. Hence, PEG-Mn-BDA exhibited apparently better selectivity to cancer cells than m-BDA did. 
Fig. 1. PEG-Mn-BDA effectively and selectively exhibited inhibitory effect on proliferation of Smmc-7721 and HCT-116 cells. (A) The viability of SMMC-7721 cells treated with PEG-Mn-BDA in different dose; (B) The viability of HCT-116 cells treated with sub-threshold concentration $(3 \mu \mathrm{M})$ and up-threshold concentration $(30 \mu \mathrm{M})$ of PEG-Mn-BDA; (C) The viability of WRL-68 cells treated with different concentration of PEG-Mn-BDA; (D) The selective inhibition of PEG-Mn-BDA on SMMC-7721 cells against WRL-68 cells. Data represent the means \pm SD of 3 different experiments. $* \mathrm{p}<0.05, * * \mathrm{p}<0.01$ and $* * * \mathrm{p}<0.005$ vs. the respective controls.

\subsection{PEG-Mn-BDA induced both fluorescence and magnetic resonance imaging}

To determine whether PEG-Mn-BDA could be absorbed into cancer cells, SMMC-7721 cells were cultured in 96-well plates for $24 \mathrm{~h}$ and exposed to $10 \mu \mathrm{M}$ of PEG-Mn-BDA for $3 \mathrm{~h}$ and the compound uptake and imaging of SMMC-7721 cells were observed using a laser scanning confocal microscope as shown in Fig. S5. When cells were treated with PEG-Mn-BDA, a bright fluorescence image was formed. It was observed that PEG-Mn-BDA was absorbed into the SMMC-7721 cells. However, the intensity of absorption was lower than that of m-BDA because of the charge transfer interaction between m-BDA and Mn(II) center with partially quenched emission. PEG-Mn-BDA was found at the periphery of the cells indicating that the compound may be absorbed mainly into the mitochondria and cytosol but not the nucleus of the cells. Based on the magnetic signal of Mn(II) ions, MR image was used to evaluate the cell absorption of PEG-Mn-BDA. It was observed that the untreated cells (control) gave dark image which was difficult to differentiate from the background (Fig 2). When PEG-Mn-BDA was added, a brighter image was observed which had sharp contrast from the background. This shows that PEG-Mn-BDA accumulated in the cells and could be a possible MRI contrast agent since its presence allowed MRI imaging.

Fig. 2 Magnetic resonance images of SMMC-7721 cells. (a) Control (SMMC-7721 cells); (b) SMMC-7721 cells treated with PEG-Mn-BDA $(10 \mu \mathrm{M})$ for $3 \mathrm{~h}$. 


\subsection{PEG-Mn-BDA induced apoptotic cell death.}

Apoptosis is the main mechanism for the anti-proliferative activity of many synthetic agents. To investigate the mechanism of PEG-Mn-BDA inhibition on cancer cells, the possibility of PEG-Mn-BDA employing apoptotic cell death pathway was determined. The apoptotic cell death of PEG-Mn-BDA was identified by DAPI, a typical nuclear condensation visualized staining. The results showed that in the untreated cells (control), the shapes of DAPI dye stained cells keep tidy suggesting more healthy cells among the control group. After incubating the cells with PEG-Mn-BDA for $24 \mathrm{~h}$, more cells become condensed or divided indicating more apoptotic cell deaths. It was observed that after treatment with PEG-Mn-BDA, the nuclei became condensed and divided into several parts with apoptotic body emerging (Fig. 3). Western blot analysis showed that the untreated cells (control) could not express caspase 3. However, when cells were treated with 5 $\mu \mathrm{M}$ PEG-Mn-BDA, caspase 3 was expressed and the intensity of the expression increased in a dose dependent manner.

Fig. 3. PEG-Mn-BDA induced apoptotic cell death. (A) SMMC-7721 cells were treated with PEG-Mn-BDA $(20 \mu \mathrm{M})$ for $24 \mathrm{~h}$, and cells were stained with DAPI and morphology of nuclei were photographed. Scale bar represents $5 \mu \mathrm{m}$. (B) SMC-7721 cells were treated with PEG-Mn-BDA and caspase-3 activation was assessed by western blot analysis.

Many compounds have been found to induce apoptosis through an ROS-mediated mitochondrial dysfunction pathway [29, 30]. To further understand the underlying molecular mechanism of apoptosis induced by PEG-Mn-BDA, ROS generation by PEG-Mn-BDA was assessed by exposing SMMC-7721 cells to different concentrations of PEG-Mn-BDA. The untreated group showed no fluorescent image of the DCFHDA dye. The study showed that treatment with PEG-Mn-BDA led to increased ROS generation in a dose dependent manner (Fig. 4). When the cells were treated with $5 \mu \mathrm{M}$ PEG-Mn-BDA, a few fluorescent image of DCFH-DA dye appeared. When the cells were treated with 10 and $30 \mu \mathrm{M}$ PEG-Mn-BDA, the percentage of 
fluorescent intensity increased significantly to 60 and 100\%, respectively, suggesting that ROS was generated in SMMC-7721 cells by PEG-Mn-BDA. When SMMC-7721 cells were pretreated with N-acetyl-L-cysteine (NAC), there were some difference in the percentage of absorption intensity between the treated and untreated when 5 and $10 \mu \mathrm{M}$ PEG-Mn-BDA were added. Moreover, when 20 and $40 \mu \mathrm{M}$ PEG-Mn-BDA was added, the NAC significantly decreased the percentage of absorption intensity, indicating that the ROS was generated by PEG-Mn-BDA. ROS generation by PEG-Mn-BDA and its the anti-proliferative effect on SMMC-7721 was assessed by MTT. It was shown that at the concentration of $5 \mu \mathrm{M}$ PEG-Mn-BDA, NAC did not show any significant reduction of the inhibition rate. However, at the concentrations of 10 and $20 \mu \mathrm{M}$ PEG-Mn-BDA, NAC decreased the inhibition rate significantly for the SMMC-7721 cancer cells (Fig. 6D), indicating that the apoptosis was mediated by ROS.

Fig.4 ROS generated by PEG-Mn-BDA contributed to the apoptotic cell death. SMMC-7721 cells were treated with various concentrations of PEG-Mn-BDA and incubated with $10 \mu \mathrm{M}$ DCFH-DA at $37{ }^{\circ} \mathrm{C}$ for 20 min. (A) fluorescence image; (B) \% of fluorescence intensity absorbed due to ROS production; (C) \% of fluorescence intensity absorbed due to ROS production. SMMC-7721 cells were exposed to 5, 10, and $20 \mu \mathrm{M}$ PEG-MnBDA for $24 \mathrm{~h}$ with or without NAC pre-treatment for $2 \mathrm{~h}$; (D) cell death was examined by MTT assay. Data represent the means \pm SD of triplicate experiments. ${ }^{*} \mathrm{p}<0.05$, ${ }^{*} \mathrm{p}<0.01$ and ${ }^{* * *} \mathrm{p}<0.005$, as compared with the untreated (control) group.

\subsection{PEG-Mn-BDA induced apoptosis through mitochondrial pathway}

The mitochondrial target imaging of compounds PEG-Mn-BDA was assessed by comparison with the well-known MitoTracker Red FM. MitoTracker Red FM binds to lipids in mitochondrial membranes. SMMC7721 cells were incubated with PEG-Mn-BDA $(10 \mu \mathrm{M})$ for 60 min at $37{ }^{\circ} \mathrm{C}$, and then MitoTracker Red FM (1 $\mu \mathrm{g} \mathrm{ml}^{-1}$ ) was added and the cells were incubated for another $60 \mathrm{~min}$ at $37^{\circ} \mathrm{C}$. When the cells were treated with PEG-Mn-BDA, green fluorescent image was shown indicating the absorption of PEG-Mn-BDA in the cells 
(Fig S6). MitoTracker Red FM was added, red fluorescent image was observed indicating presence of MitoTracker Red in the cell. When the cells were incubated with both PEG-Mn-BDA and Mitotracker Red, most of the cells showed overlapped images (yellow), indicating mitochondrial target imaging of PEG-MnBDA. However, a few cells showed green images indicating that PEG-Mn-BDA may target other organelles apart from mitochondria. To verify PEG-Mn-BDA-mediated ROS generation within cells, the changes in apoptotic molecules related to mitochondria pathway in SMMC-7721 cells were examined. Regulation of the mitochondrial membrane-permeability following the apoptotic pathway due to induction of ROS has been observed. Loss of mitochondrial inner transmembrane potential $(\Delta \Psi \mathrm{m})$ is often observed to be associated with early stages of apoptosis $[31,32]$. The ability of PEG-Mn-BDA to depolarize the mitochondrial membrane potential was detected by Rhodamine 123 staining (Fig. S6). It was observed that when 3, 10 and $30 \mu \mathrm{M}$ PEGMn-BDA were added to the cells, the intensity of light absorption was significantly decreased in a dose dependent manner. When the SMMC-7721 cells were either untreated or treated with CsA, a mitochondrial membrane protector, the percentage of the intensity of absorption was $100 \%$ indicating the cells were healthy. When the cells were treated with PEG-Mn-BDA, the percentage intensity of absorption decreased to $61 \%$ suggesting depolarization of mitochondrial membrane potential. When the cells were then pretreated with CsA, it was shown that the intensity of fluorescence absorption returned to the original value suggesting that the mitochondrial membrane polarization may be induced by the PEG-Mn-BDA. Pretreatment of cells with CsA led to decreased inhibition rate of PEG-Mn-BDA on SMMC-7721 cells. At the concentrations of 0 and $5 \mu \mathrm{M}$, there was no significant difference between the inhibition rates of the two groups. However, at the concentrations of 10 and $20 \mu \mathrm{M}$ PEG-Mn-BDA, CsA significantly decreased the inhibition rate of PEG-MnBDA on SMMC-7721 cells, which suggests that mitochondrial membrane potential depolarization contributed to the apoptotic cell death.

Fig. 5 PEG-Mn-BDA exhibited an inhibitory effect on LDH-A activities in SMMC-7721 cells. SMMC-7721 cells were treated with $10 \mu \mathrm{M}$ PEG-Mn-BDA, $150 \mu \mathrm{M} \mathrm{CoCl}_{2}$ and $150 \mu \mathrm{M}$ DFO and the LDH-A activities were examined. 
3.6 PEG-Mn-BDA exhibited an inhibitory effect on LDH-A activities in SMMC-7721 cells.

To examine whether PEG-Mn-BDA have inhibitory effect on LDH-A in SMMC-7721 cells, cells were treated with $10 \mu \mathrm{M}$ PEG-Mn-BDA for $24 \mathrm{~h}$ and LDH-A activities were examined. It was shown that the LDHA activity of the untreated cells (control) was $100 \%$. When the cells were treated with $10 \mu \mathrm{M}$ PEG-Mn-BDA, the LDH-A activity was decreased to $58 \%$ (Fi.g.5). When the inhibitory effect of PEG-Mn-BDA was compared with that of BDA, there was no significant difference between them (Fig. S7). The inhibitory effect of PEG-Mn-BDA on LDH-A was confirmed by western blot. It was shown that although LDH-A was expressed on the untreated control cells, treatment with either DFO or $\mathrm{CoCl}_{2}$ increased the expression of LDHA. When PEG-Mn-BDA was added to either DFO treated or $\mathrm{CoCl}_{2}$ treated cells, the expression of LDH-A was decreased. This result suggests that PEG-Mn-BDA may also affect the glycolytic pathway. When the cells were treated with only PEG-Mn-BDA, LDH-A expression was greatly reduced.

Fig. 6 PEG-Mn-BDA exhibited higher anti-proliferative activity on cancer cells in hypoxic conditions than in normoxic conditions. Various concentrations of PEG-Mn-BDA were added to SMMC-7721 or $\mathrm{CoCl}_{2}$ treated SMMC 7721. Data represent the means \pm SEM of triplicate experiments. $* p<0.05$ and $* * p<0.01$ vs. the respective controls.

To investigate the anti-proliferative activity of PEG-Mn-BDA on cancer cells in hypoxic conditions, SMMC7721 was pretreated with hypoxia mimetic agent, $\mathrm{CoCl}_{2}$, to stimulate hypoxic condition in the cells. As shown (Fig. 6), when SMMC-7721 cells were treated with 0,5 or $40 \mu \mathrm{M}$ of $\mathrm{CoCl}_{2}$, there was no significance changes in survival rate of the cells. However, when 10 or $20 \mu \mathrm{M}$ PEG-Mn-BDA was added, the survival rate of the $\mathrm{CoCl}_{2}$ treated cells decreased significantly. It was also found that the survival rate of $\mathrm{CoCl}_{2}$ treated cells was 
higher than SMMC-7721 cells when $40 \mu$ M PEG-Mn-BDA was added. This result showed that SMMC-7721 cells were more sensitive to PEG-Mn-BDA $(5-20 \mu \mathrm{M})$ in hypoxic conditions than in normoxic conditions.

\subsection{PEG-Mn-BDA selectively inhibited tumor growth in vivo}

To examine the antitumor activity of PEG-Mn-BDA in vivo, we developed a mouse xenograft model of Hep-A cells in ICR mice. It was shown that all the three experimental groups had smaller volume of tumor than the control. The administration of PEG-Mn-BDA (20 or $40 \mathrm{mg} / \mathrm{kg}$, once a day) inhibited tumor growth in the mice in a dose-dependent manner (Fig. S8 and Table S2), though the tumor inhibition rate was lower than that of 5-FU. Treatment with 5-FU significantly reduced body weight, splenic index and thymus in the mice, whereas no significant changes were observed in the PEG-Mn-BDA-treated mice (Fig. 7) which showed that PEG-Mn-BDA selectively targeted the tumor without affecting the healthy organs.

Fig. 7. PEG-Mn-BDA did not cause harm to healthy organs. (A) Lean body weight (B) Thymus index (C) Spleen index and (D) Liver index were calculated. Data represent the means \pm SEM. $n=10, * p<0.05$ and $* * \mathrm{p}<0.01$ vs. control.

\subsection{Discussion}

Molecular imaging is a powerful tool for early identification and surgical procedures. Since each imaging technique has its own advantages and limitations, multimodal imaging technique is necessary to take advantage of complementary and reliable information of the individual imaging technique. In order to obtain an anticancer drug with bimodal imaging ability, PEG-Mn-BDA was synthesized. In this study, the anticancer effect, the mechanism of cancer cell death and the bimodal imaging ability of PEG-Mn-BDA was investigated and compared with m-BDA. It was found that PEG-Mn-BDA exerted inhibitory effect in a dose dependent manner on all the three types of cancer cells, with the sensitivity of the cells increasing in the order HepG-2, HCT-116 and SMMC-7721. The inhibitory effect of PEG-Mn-BDA was again demonstrated in vivo against a 
mouse hepatocellular carcinoma xenograft. When the anti-proliferative activity of PEG-Mn-BDA was compared with m-BDA, it was found out that PEG-Mn-BDA appeared to have a better inhibitory effect on both SMMC-7721 and HCT-116 cells than m-BDA. The goal of any therapeutic strategy is to kill the tumor cells with limited detrimental effect to normal cell function. It was therefore important to determine the cancerselective killing without compromising normal cell function. Both m-BDA and PEG-Mn-BDA were found to be selective towards cancer cells compared to non-malignant cells with PEG-Mn-BDA being more selective than m-BDA at all concentrations used. It was shown that at concentrations of 3, 10 and $30 \mu \mathrm{M}$, PEG-MnBDA had 11.12, 9.34 and $22.42 \%$ better selectivity than m-BDA, respectively. PEG-Mn-BDA also demonstrated selective killing of tumor without affecting the normal tissues in vivo. It was shown that PEGMn-BDA had no adverse effect on the body weight, thymus, spleen and the liver. This will make PEG-MnBDA safer to use since its inhibitory effects on cancer cells will not have devastating consequences on healthy proliferating cells. It has been observed that cancer cell lines have higher mitochondrial membrane potential than that of normal cells. This selectivity of PEG-Mn-BDA may be due to its ability to induce cell death via different pathways and its excellent transport system into the cells. Studies have shown that iron transport proteins such as transferrin receptors are over expressed on cancer cells [33, 34], and manganese complexes are transported into cancer cells using the same transport system [35]. PEG-Mn-BDA is therefore suspected to be transported into the SMMC-7721 cells by these iron transport proteins. The cell imaging showed that both m-BDA and PEG-Mn-BDA were able to pass through the cell membrane and settled mostly at the periphery of the cell. This shows that the compounds interacted mostly with mitochondria but not much with the nucleus. PEG-Mn-BDA was demonstrated to be a potential MRI contrast agent since its presence was able to induce MRI image. This makes PEG-Mn-BDA a very good candidate over m-BDA on account of its ability to be used as bimodal imaging compound. PEG-Mn-BDA was able to induce the expression of caspase 3 in dose dependent manner to induce apoptosis. It was observed that PEG-Mn-BDA was able to generate excessive ROS to trigger apoptosis by activating caspase 3. Studies have shown that increase ROS production could lead to mitochondrial membrane potential collapse [36]. It was shown from this study that disruption of the mitochondrial membrane potential was an important factor that contributed to apoptotic cell death induced by PEG-Mn-BDA. 
It has long been known that inhibition of LDH-A is an important indirect way of targeting mitochondria to induce apoptosis [37]. This repressed LDH-A levels redirects ATP production via oxidative phosphorylation thereby increasing the ROS production by the mitochondria and therefore causing the cancer cells to induce apoptosis. The possibility of the effect of PEG-Mn-BDA on LDH-A activity was then considered. It was found that PEG-Mn-BDA significantly decreased the levels of the LDH-A. It could then be deduced that PEG-MnBDA induced apoptosis partly by inhibiting the activity of LDH-A. Reduction of LDH-A activity by PEG-MnBDA favored the entry of pyruvate into the mitochondria and increased oxygen consumption. The increased in oxidative phosphorylation led to increased production of ROS which induced the observed apoptosis by depolarizing the mitochondrial membrane potential. Reduction of LDH-A activity also decreases the availability of $\mathrm{NAD}^{+}$and therefore suppresses glycolysis. Finally, it was observed that SMMC-7721 cancer cells were more sensitive to PEG-Mn-BDA in hypoxic condition than in normoxic condition. This makes PEG-Mn-BDA a good candidate for anticancer agent since most cancer cells are mostly found in hypoxic environment. Taking together, our study showed that PEG-Mn-BDA inhibits the lactate dehydrogenase A which reduces the ATP production via glycolysis, and increases oxidative phosphorylation which generates excessive ROS, and induces cancer cell apoptosis by depolarizing mitochondrial membrane potential.

\section{Conclusion}

In conclusion, our study demonstrated that PEG-Mn-BDA exerted antineoplastic effects on SMMC-7721, HCT-116 and HepG-2 cells in a dose dependent manner and the anti-proliferative effect is comparable to BDA. The compound can be absorbed into the mitochondrial and the cytosol. Though the fluorescence intensity of PEG-Mn-BDA was lower than m-BDA, it has additional advantages of inducing MRI images. It inhibits the lactate dehydrogenase A which reduces the ATP production via glycolysis, and increases oxidative phosphorylation which generates excessive ROS, and induces cancer cell apoptosis by depolarizing mitochondrial membrane potential. By our study, we identified PEG-Mn-BDA as a promising multifunctional agent for treatment and bimodal imaging of cancer.

\section{Acknowledgments}


Financial support from National Science Foundation of China (21271090, 21571085)and Hi-Technical Innovation Foundation of Jiangsu Province (BC2012072) and the open Fund of Beijing National Laboratory for Molecular Sciences (BNLMS20150123).

\section{Reference}

[1] M. López-Lázaro, A new view of carcinogenesis and an alternative approach to cancer therapy,Mol Med. 16 (2010) 144-153.

[2] E.A. Liberman, V.P. Topaly, L.M. Tsofina, A.A. Jasaitis, V.P. Skulachev, Mechanismof coupling of oxidative phosphorylation and the membrane potential of mitochondria, Nat. 222 (1969) 1076-1078.

[3] X.-W. Ma, N.-Q. Gong, L. Zhong, J.-D. Sun, X.-J. Liang, Future of nanotherapeutics: Targeting the cellular sub-organelles, Biomater. 97 (2016) 10-21.

[4] H. Li, J. Chen, W. Zen, X. Xu, Y. Xu, Q. Chen, Effect of hypoxia inducible factor-1 antisense oligonucleotide on liver cancer, J. Clin. Med. 8 (2015) 12650-12655.

[5] H. Yoon, S.H. Shin, D.H. Shin, Y.S. Chun, J.W. Park. Differential roles of Sirt1 in HIF-1 alpha and HIF-2 alpha mediated hypoxic responses, Bio. Chem. Bio. Phys, 444 (2014) 36-43.

[6] H. Xiong, S. Du, J. Ni, J.P. Zhou, J. Yao, Mitochondria and nuclei dual-targeted heterogeneous hydroxyapatite nanoparticles for enhancing therapeutic efficacy of doxorubicin. Biomater. 94 (2016) 7483.

[7] P. Dutta, A. Le, D.L. Vander, T. Tsukamoto, G.V. Martinez, C.V. Dang, Evaluation of LDH-A and glutaminase inhibition in vivo by hyperpolarized C-13-pyruvate magnetic resonance spectroscopy of tumors, Cancer. Res, 73 (2013) 4190-4195.

[8] X. Zhai, Y. Yang, J. Wan, R. Zhu, Y. Wu, Inhibition of LDH-A by oxamate induces G(2) / Marrest, apoptosis and increases radio sensitivity in nasopharyngeal carcinoma cells, Oncology Rep. 30 (2013) 2983-2991. 
[9] M. Manerba, L. Di, L. Fiume, M. Roberti, M. Recanatin, G. Di Stefano, Lactate dehydrogenase inhibitors sensitize lymphoma cells to cisplatin without enhancing the drug effects on immortalized normal lymphocytes, Eur. J. Pharma. Sci, 74 (2015) 95-102.

[10] A. Le, C.R. Cooper, A.M. Gouw, R. Dinavahi, A. Maitra, L.M. Deck, Inhibition of lactate dehydrogenase A induces oxidative stress and inhibits tumor progression, Proc. Nat.Aca. Sci, 107 (2010) 2037-2042.

[11] P. Maiso, D. Huynh, M. Moschetta, A. Sacco, Y. Aljawai, Y. Mishima, J.M. Asara, A.M. Roccaro, A.C. Kimmelman, I.M. Ghobrial,Metabolic signature identifies novel targets for drug resistance in multiple myeloma, Cancer Res. 75 (2015) 2071-2082.

[12] J.J. Xue, Q.Y. Chen, M..Y. Kong, C.Y. Zhu, Z.R. Gen, Z.L. Wang. Synthesis, cytotoxicity for mimics of catalase: Inhibitors of lactate dehydrogenase and hypoxia inducible factor, Eur. J. Med. Chem. 80 (2014) $1-7$.

[13] D.E. Zhou, Q.Y. Chen, Y. Qi, H.J. Fu, Z. Li, K.D. Zhao, J. Gao, Anticancer activity, attenuation on the absorption of calcium in mitochondria, and catalase activity for manganese complexes of $\mathrm{N}$-substituted di(picolyl)amine, Inorg. Chem. 50 (2011) 6929-6937.

[14] M.S. Golub, C.E. Hogrefe, S.L. Germann, T.T. Tran, J.L. Beard, F.M. Crinella, Neurobehavioral evaluation of rhesus monkey infants fed cow's milk formula, soyformula, or soy formula with added manganese, Neurotoxi. Terat. 27(2005)615-27.

[15] K.M. Erikson, T. Syversen, J.L. Aschner, M. Aschner. Interactions between excessive manganese exposures and dietary iron-deficiency in neurodegeneration. Environ,Toxicol. Pharmacol. 19 (2005) 415421.

[16] C.R. Gordijo, A.Z. Abbasi, M.A. Amini, H.Y. Lip, A. Maeda, P. Cai P, Design of hybrid $\mathrm{MnO}_{2}$-polymerlipid nanoparticles with tunable oxygen generation rates and tumor accumulation for cancer treatment, Adv. Funct. Mater. 25 (2015) 1858-1872.

[17] Z.W. Wang, Q.Y. Chen, Q.S. Liu, Manganese(II) complexes of quinoline derivatives: characterization, catalase activity, interaction with mitochondria and anticancer activity, Transit. Met. Chem. 39 (2014) 917-924. 
[18] J. Liu, W.J. Guo, J. Li, X. Li, J. Geng, Q.Y. Chen, J. Gao. Tumor-targeting novel manganese complex induces ROS-mediated apoptotic and autophagic cancer cell death, Inter. J. Mol. Med. 35 (2015) 607-616.

[19] X. Li, K.D. Zhao, W.J. Guo, X. Liu, J. Liu, J. Gao, Q.Y. Chen, Y.D. Bai, A novel manganese complex LMnAc selectively kills cancer cells by induction of ROS-triggered and mitochondrial-mediated cell death, Science China: Life Sci. 57 (2014) 998-1010.

[20] M. Yu, S.L. Ambrose, Z. L. Whaley, S. J. Fan, J. D. Gorden, R. J. Beyers, D. D. Schwartz, C. R. Goldsmith, A mononuclear manganese(II) complex demonstrates a strategy to simultaneously image and treat oxidative stress, J. Am. Chem. Soc. 136 (2014) 12836 - 12839.

[21] Q. Chen, L. Wang, L. Zhang, W. Guo, J. Gao, Targeting cancer cells through Mn(II)-dpagrafted silica nanoparticles, Science China-Chem. 53 (2010) 1728-1731.

[22] H.L.M. Cheng, I. E. Haedicke, W.R. Cheng, J.T. Nofiele, X.A. Zhang, Gadolinium-free T-1 contrast agents for MRI: tunable pharmacokinetics of a new class of manganese porphyrins, J. Magn. Reson. Imag. 40 (2014) 1474-1480.

[23] J. Kim, Y. Piao, T. Hyeon, Multifunctional nanostructured materials for multimodal imaging, and simultaneous imaging and therapy, Chem. Soc. Rev. 38 (2009) 372-390.

[24] K. Poliraju, V. Raviraj, C.S. Chiang, K. C. Hwang, Nano-graphene oxide-mediated in vivo fluorescence imaging and bimodal photodynamic and photothermal destruction of tumors, Biomater. 95 (2016) 1-10.

[25] D.E. Lee, H. Koo, I.C. Sun, J.H. Ryu, K. Kim, I.C. Kwon, Multifunctional nanoparticles for multimodal imaging and theragnosis, Chem. Soc. Rev.41 (2012) 2656-2672.

[26] B. Sahoo, K.S.P. Devi, S. Dutta, T.K. Maiti, P. Pramanik, D. Dhara, Biocompatiblemesoporous silicacoated superparamagnetic manganese ferrite nanoparticles for targeted drug delivery and MR imaging applications, J. Colloid Interface. Sci. 431 (2014) 31-41.

[27] Z. Li, Q.Y. Chen, P.D. Wang, Y. Wu, Multifunctional BODIPY derivatives to image cancer cells and sense copper(II) ions in living cells, Rsc. Adv. 3 (2013) 5524-5528.

[28] H.H. Yang, B.J. Han, W. Li, Y.J. Liu, X.Z. Wang, Synthesis, molecular structure, DNA/protein binding, cytotoxicity, apoptosis, reactive oxygen species, and mitochondrial membrane potential of dibenzoxanthenes derivatives, J. Membr. Biol. 248 (2015) 951 -965. 
[29] A.C. Hearps, J. Burrows, C.E. Connor, G.M. Woods, R.M. Lowenthal, S.J. Ragg. Mitochondrial cytochrome c release precedes transmembrane depolarisation and caspase- 3 activationduring ceramideinduced apoptosis of Jurkat T cells, Apoptosis. 7 (2002) 387-394.

[30] J.D. Ly, D.R. Grubb, A. Lawen, The mitochondrial membrane potential (Delta psi m) in apoptosis, an update, Apoptosis. 8 (2003) 115-128.

[31] S.R. Chowdhury, S. Sengupta, S. Biswas, R. Sen, T.K. Sinha, R.K. Basak, Low fucosecontaining bacterial polysaccharide facilitate mitochondria-dependent ROS-induced apoptosis of human lung epithelial carcinoma via controlled regulation of MAPKs-mediated Nrf2/Keap1 homeostasis signaling, Mol. Carcinog. 54 (2015) 1636-1655.

[32] X.L. Xu, J. Shao, Q.Y. Chen, C.H. Li, M.Y. Kong, F. Fang, L. Ji, D. Boison, T. Huang, J. Gao, C.J. Feng, A $\mathrm{Mn}$ (II) complex of boradiazaindacene (BODIPY) loaded graphene oxide as both LED light and $\mathrm{H}_{2} \mathrm{O}_{2}$ enhanced anticancer agent, J. Inorg. Biochem. 159 (2016) 1-6.

[33] S. Dixit, T. Novak, K. Miller, Y. Zhu, M.E. Kenney, A.M. Broome, Transferrin receptor-targeted theranostic gold nanoparticles for photosensitizer delivery in brain tumors, Nanoscale. 7 (2015)17821790.

[34] H.O. Habashy, D.G. Powe, C.M. Staka, E.A. Rakha, G. Ball, A.R. Green, Transferrin receptor (CD71) is a marker of poor prognosis in breast cancer and can predict response to tamoxifen, Breast Cancer. Res. Tr. 119 (2010) 283-293.

[35] L. Yao, Q.Y. Chen, X.L. Xu, Z. Li, X.M. Wang, Interaction of manganese(II) complex with apotransferrin and the apotransferrin enhanced anticancer activities, Spectrochim. Acta, Part A. 105 (2013) 207-212.

[36] L.A.A. Gilliam, K.H. Fisher-Wellman, C.T. Lin, J.M. Maples, B.L. Cathey, P.D. Neufer, The anticancer agent doxorubicin disrupts mitochondrial energy metabolism and redox balance in skeletal muscle, Free Radical Biol. Med. 65 (2013)988-996.

[37] F.J. Hes, J.W.M. Hoppener, R.B. Luijt, C.J.M. Lips, Von Hippel-Lindau Disease, Heredit. Cancer Clin. Pract. 3 (2005) 171-178. 
Figure captions

Scheme 1 Synthetic routes of PEG-Mn-BDA.

Fig. 1. PEG-Mn-BDA effectively and selectively exhibited inhibitory effect on proliferation of Smmc-7721 and HCT-116 cells. (A) The viability of SMMC-7721 cells treated with PEG-Mn-BDA in different dose; (B) The viability of HCT-116 cells treated with sub-threshold concentration $(3 \mu \mathrm{M})$ and up-threshold concentration $(30 \mu \mathrm{M})$ of PEG-Mn-BDA; (C) The viability of WRL-68 cells treated with different concentration of PEG-Mn-BDA; (D) The selective inhibition of PEG-Mn-BDA on SMMC-7721 cells against WRL-68 cells. Data represent the means \pm SD of 3 different experiments. ${ }^{*} \mathrm{p}<0.05$, $* * \mathrm{p}<0.01$ and $* * * \mathrm{p}<0.005$ vs. the respective controls.

Fig. 2 Magnetic resonance images of SMMC-7721 cells. (a) Control (SMMC-7721 cells); (b) SMMC-7721 cells treated with PEG-Mn-BDA $(10 \mu \mathrm{M})$ for $3 \mathrm{~h}$.

Fig. 3. PEG-Mn-BDA induced apoptotic cell death. (A) SMMC-7721 cells were treated with PEG-Mn-BDA $(20 \mu \mathrm{M})$ for $24 \mathrm{~h}$, and cells were stained with DAPI and morphology of nuclei were photographed. Scale bar represents $5 \mu \mathrm{m}$. (B) SMC-7721 cells were treated with PEG-Mn-BDA and caspase-3 activation was assessed by western blot analysis.

Fig.4 ROS generated by PEG-Mn-BDA contributed to the apoptotic cell death. SMMC-7721 cells 
were treated with various concentrations of PEG-Mn-BDA and incubated with $10 \mu \mathrm{M}$ DCFH-DA at $37{ }^{\circ} \mathrm{C}$ for $20 \mathrm{~min}$. (A) fluorescence image; (B) \% of fluorescence intensity absorbed due to ROS production; (C) \% of fluorescence intensity absorbed due to ROS production. SMMC-7721 cells were exposed to 5, 10, and $20 \mu \mathrm{M}$ PEG-Mn-BDA for $24 \mathrm{~h}$ with or without NAC pre-treatment for $2 \mathrm{~h}$; (D) cell death was examined by MTT assay. Data represent the means \pm SD of triplicate experiments. ${ }^{*} \mathrm{p}<0.05,{ }^{* *} \mathrm{p}<0.01$ and ${ }^{* * *} \mathrm{p}<0.005$, as compared with the untreated (control) group.

Fig. 5. PEG-Mn-BDA exhibited an inhibitory effect on LDH-A activities in SMMC-7721 cells. SMMC-7721 cells were treated with $10 \mu \mathrm{M}$ PEG-Mn-BDA, $150 \mu \mathrm{M} \mathrm{CoCl}_{2}$ and $150 \mu \mathrm{M}$ DFO and the LDH-A activities were examined.

Fig. 6. The anti-proliferative activity of PEG-Mn-BDA on cancer cells in hypoxic conditions and normoxic conditions. Various concentrations of PEG-Mn-BDA were added to SMMC-7721 or $\mathrm{CoCl}_{2}$ treated SMMC 7721. Data represent the means \pm SEM of 3 different experiments. ${ }^{*} \mathrm{p}<0.05$ and $* * \mathrm{p}<0.01$ vs. the respective controls.

Fig. 7. PEG-Mn-BDA did not cause harm to healthy organs. (A) Lean body weight (B) Thymus index (C) Spleen index and (D) Liver index were calculated. Data represent the means \pm SEM. $\mathrm{n}=10,{ }^{*} \mathrm{p}<0.05$ and $* * \mathrm{p}<0.01$ vs. control. 
$\underset{\mathrm{HPEG}}{\mathrm{H}} \underset{\mathrm{N}}{\mathrm{C}_{-}^{-}}-\mathrm{OH}+\mathrm{MnCl}_{2}+$

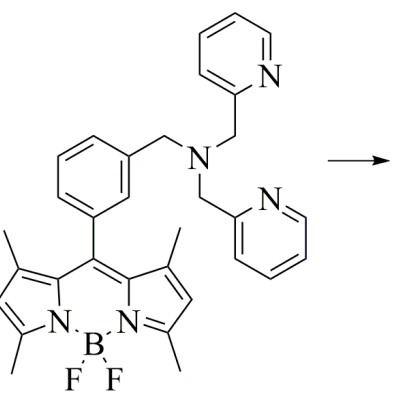

m-BDA

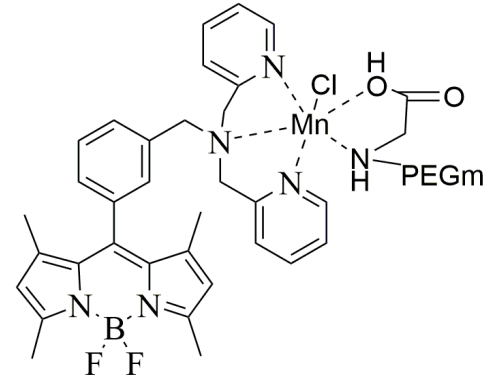

PEG-Mn-BDA

$$
\mathrm{m}-\mathrm{PEG}=\mathrm{CH}_{3} \mathrm{O} \sim \mathrm{O} \mathrm{\gamma}_{\mathrm{n}} \mathrm{O}^{-}
$$

Scheme 1 Synthetic routes to PEG-Mn-BDA. 

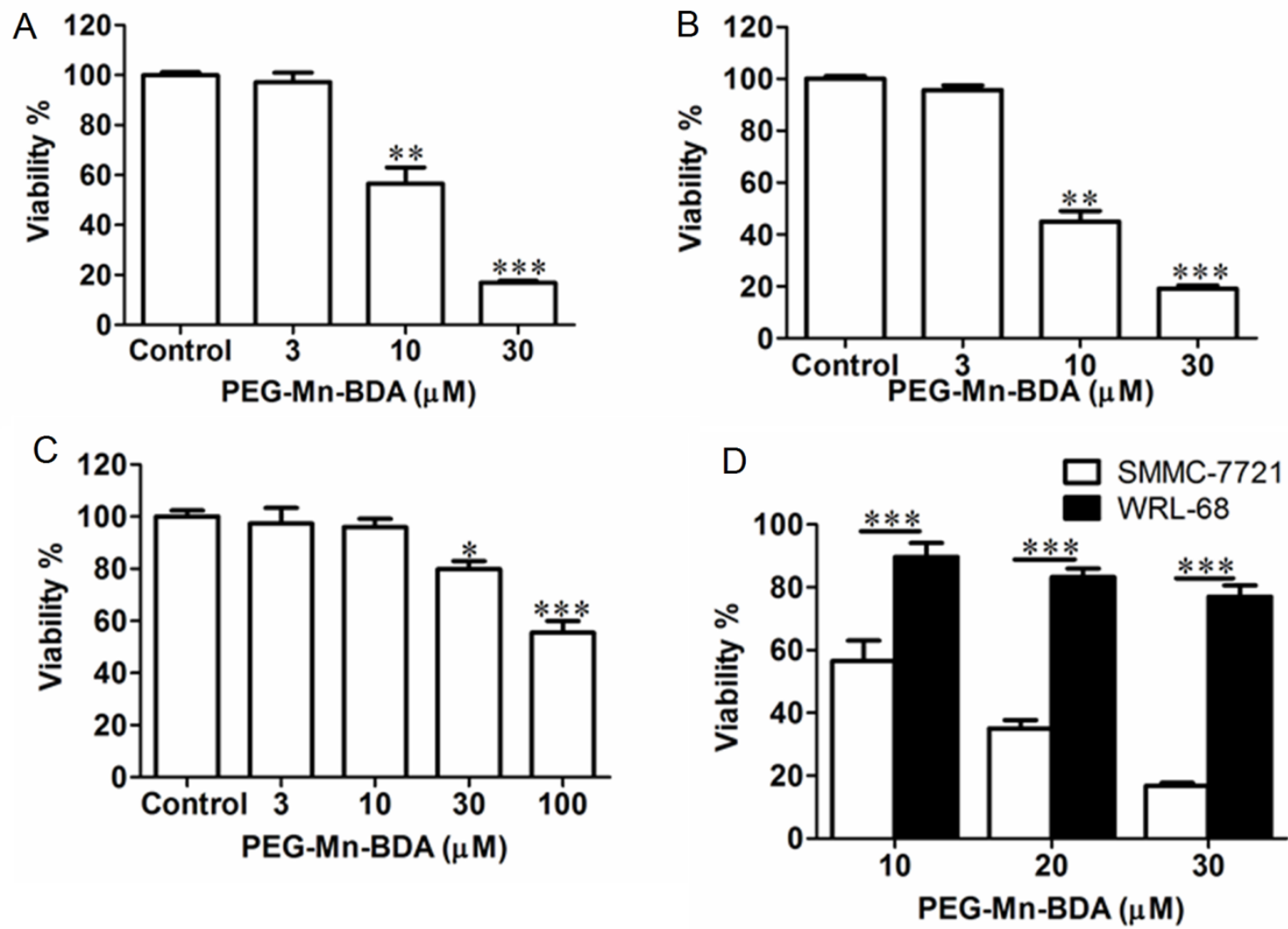

Fig. 1. PEG-Mn-BDA effectively and selectively exhibited inhibitory effect on proliferation of Smmc-7721 and HCT-116 cells. (A) The viability of SMMC-7721 cells treated with PEG-Mn-BDA in different dose; (B) The viability of HCT-116 cells treated with sub-threshold concentration $(3 \mu \mathrm{M})$ and up-threshold concentration (30 $\mu \mathrm{M})$ of PEG-Mn-BDA; (C) The viability of WRL-68 cells treated with different concentration of PEG-Mn-BDA; (D) The selective inhibition of PEG-Mn-BDA on SMMC-7721 cells against WRL-68 cells. Data represent the means \pm SD of 3 different experiments. ${ }^{*} \mathrm{p}<0.05$, $* * \mathrm{p}<0.01$ and $* * * \mathrm{p}<0.005$ vs. the respective 
controls.

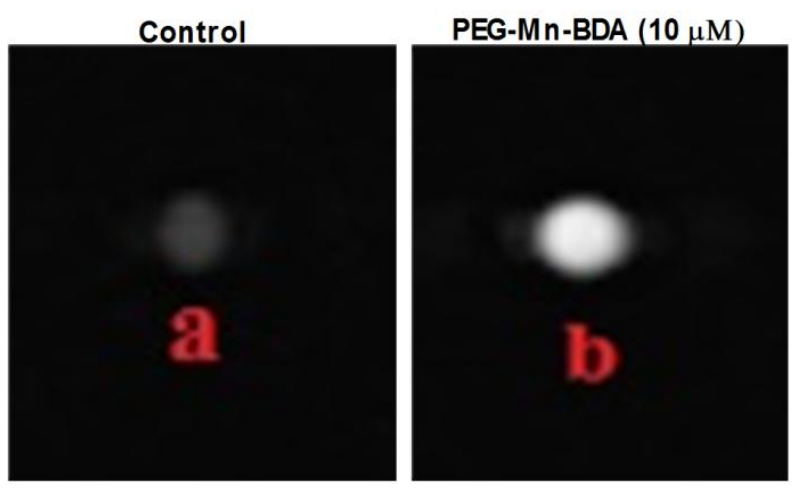

Fig. 2 Magnetic resonance images of SMMC-7721 cells. (a) Control (SMMC-7721 cells); (b) SMMC-7721 cells treated with PEG-Mn-BDA $(10 \mu \mathrm{M})$ for $3 \mathrm{~h}$. 

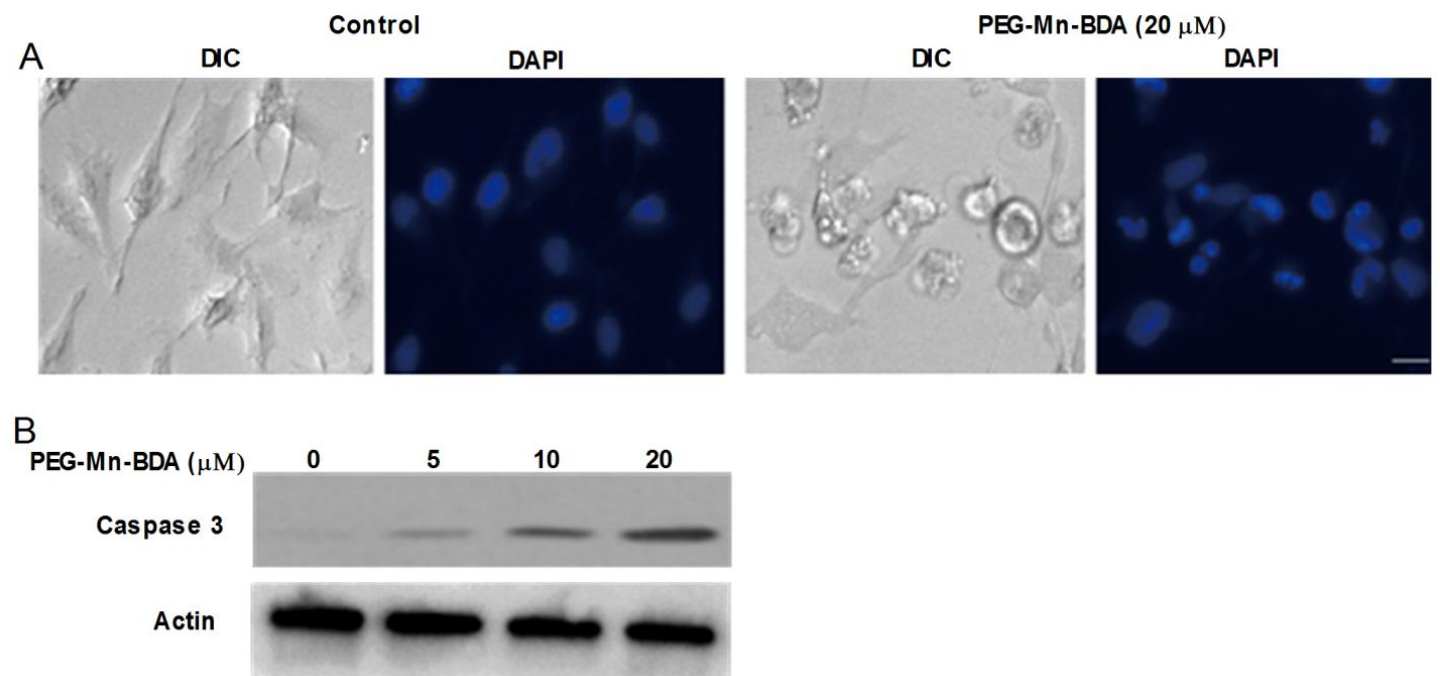

Fig. 3. PEG-Mn-BDA induced apoptotic cell death. (A) SMMC-7721 cells were treated with PEG-Mn-BDA $(20 \mu \mathrm{M})$ for $24 \mathrm{~h}$, and cells were stained with DAPI and morphology of nuclei were photographed. Scale bar represents $5 \mu \mathrm{m}$. (B) SMC-7721 cells were treated with PEG-Mn-BDA and caspase-3 activation was assessed by western blot analysis. 

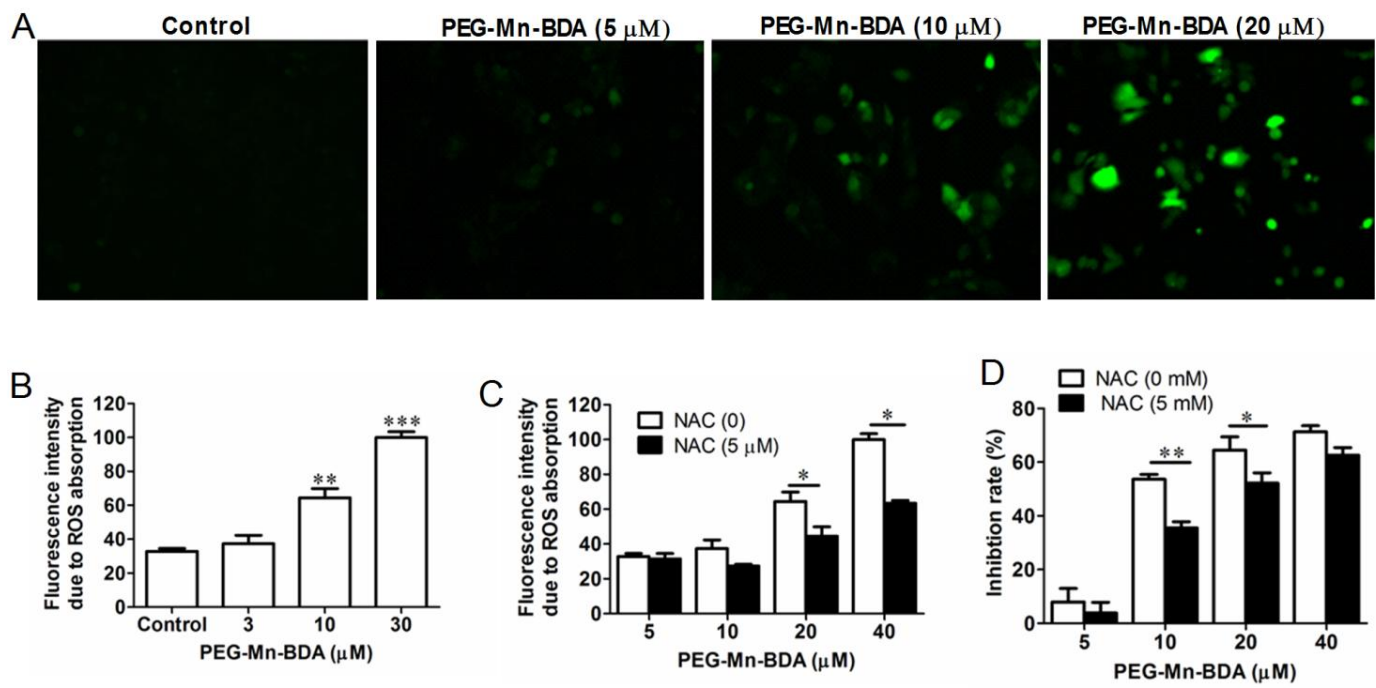

Fig.4 ROS generated by PEG-Mn-BDA contributed to the apoptotic cell death. SMMC-7721 cells were treated with various concentrations of PEG-Mn-BDA and incubated with $10 \mu \mathrm{M}$ DCFH-DA at $37^{\circ} \mathrm{C}$ for 20 min. (A) fluorescence image; (B) \% of fluorescence intensity absorbed due to ROS production; (C) \% of fluorescence intensity absorbed due to ROS production. SMMC-7721 cells were exposed to 5, 10, and $20 \mu \mathrm{M}$ PEG-Mn-BDA for $24 \mathrm{~h}$ with or without NAC pre-treatment for $2 \mathrm{~h}$; (D) cell death was examined by MTT assay. Data represent the means \pm SD of triplicate experiments. ${ }^{*} \mathrm{p}<0.05,{ }^{* *} \mathrm{p}<0.01$ and ${ }^{* * *} \mathrm{p}<0.005$, as compared with the untreated (control) group. 
A

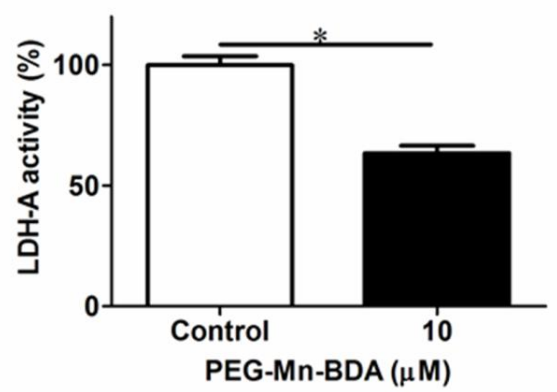

B

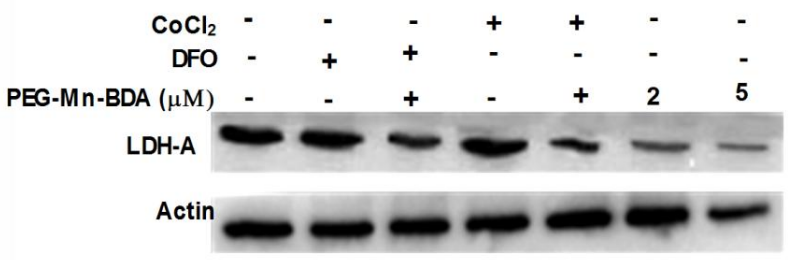

Fig. 5. PEG-Mn-BDA exhibited an inhibitory effect on LDH-A activities in SMMC-7721 cells.

SMMC-7721 cells were treated with $10 \mu \mathrm{M}$ PEG-Mn-BDA, $150 \mu \mathrm{M} \mathrm{CoCl}_{2}$ and $150 \mu \mathrm{M}$ DFO and the LDH-A activities were examined. 


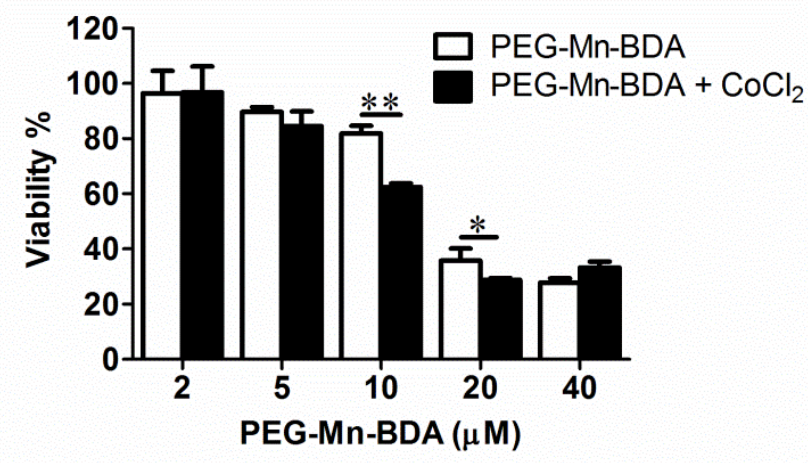

Fig. 6. The anti-proliferative activity of PEG-Mn-BDA on cancer cells in hypoxic conditions and normoxic conditions. Various concentrations of PEG-Mn-BDA were added to SMMC-7721 or $\mathrm{CoCl}_{2}$ treated SMMC 7721. Data represent the means \pm SEM of 3 different experiments. ${ }^{*} \mathrm{p}<0.05$ and ${ }^{* *} \mathrm{p}<0.01$ vs. the respective controls. 

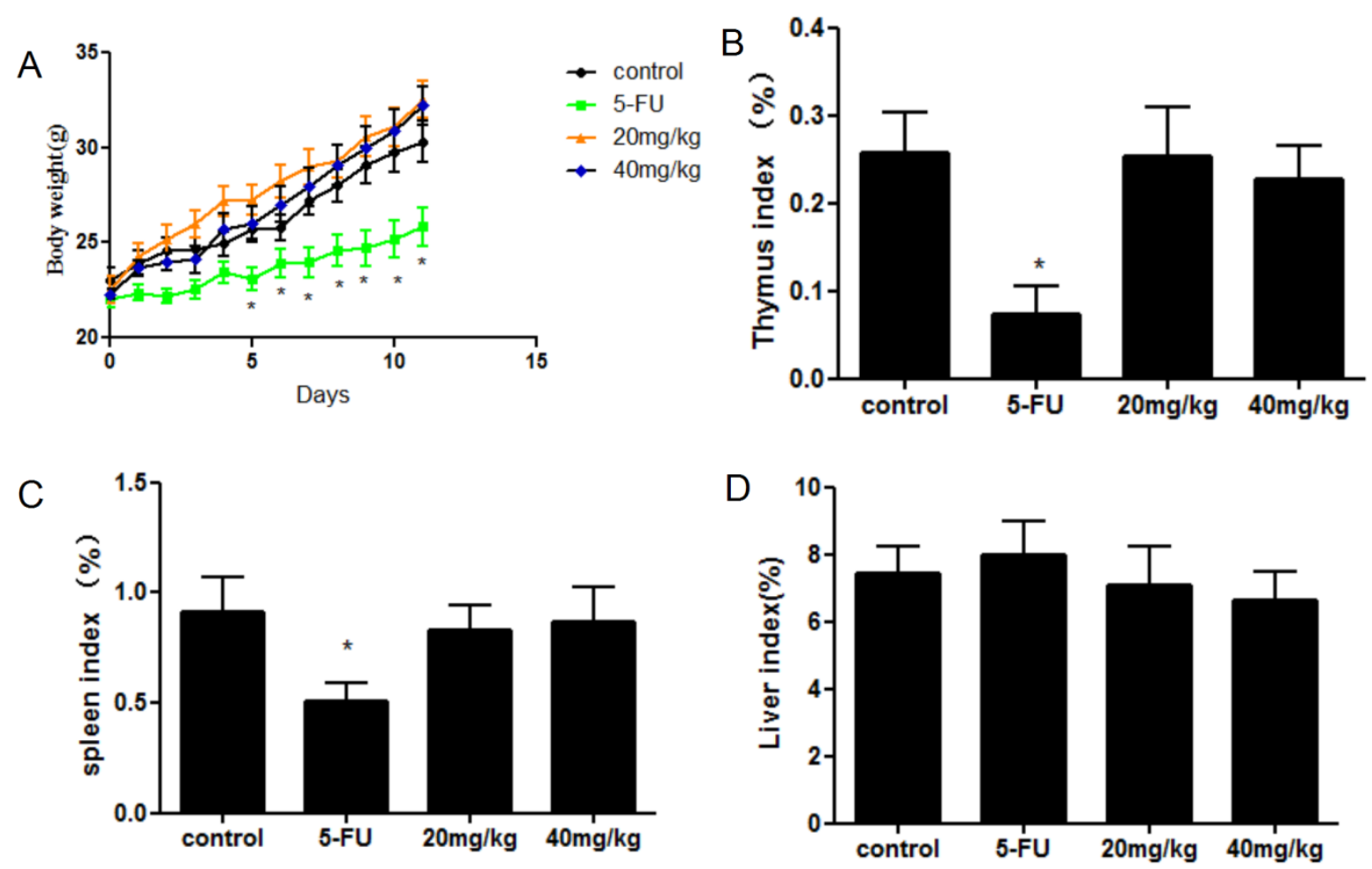

Fig.7. PEG-Mn-BDA did not cause harm to healthy organs. (A) Lean body weight; (B) Thymus index; (C) Spleen index and (D) Liver index were calculated. Data represent the means \pm SEM. $\mathrm{n}=10, * \mathrm{p}<0.05$ and $* * \mathrm{p}<0.01$ vs. control. 


\section{A mitochondria targeting Mn nanoassembly of BODIPY for LDH-A, mitochondria modulated therapy and bimodal imaging of cancer}

Daniel Boison, Wen-Long Lu, Qin-Mei Xu, Huang Yang,Tao Huang, Qiu-Yun Chen, Jing Gao, Yao Zhao

A Mn nanoassembly of BODIPY is constructed for LDH-A, mitochondria modulated therapy and bimodal imaging of cancer.

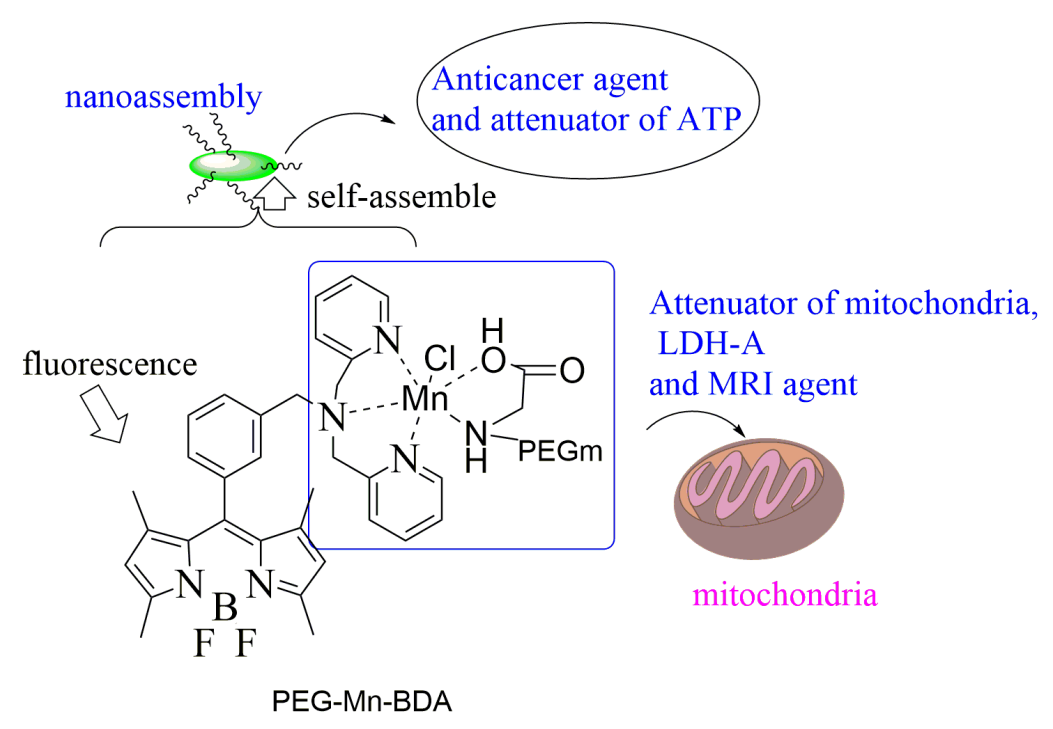

